\title{
EDUCAÇÃO MUSICAL INCLUSIVA EM UM CURSO DE LICENCIATURA EM MÚSICA: RELATO DE UMA EXPERIÊNCIA
}

Maria Cecilia de A. R. Torres Nisiane Franklin da Silva

DOI: http://dx.doi.org/10.19179/2F2319-0868/2F767

TORRES, Maria Cecilia de A. R.; SILVA, Nisiane Franklin da. Educação musical inclusiva em um curso de licenciatura em música: relato de uma experiência. Revista da FUNDARTE. Montenegro, p.215-231, ano 20, oㅜ 40, janeiro/março de 2020.

Disponível em: http://.seer.fundarte.rs.gov.br/index.php/RevistadaFundarte/index> 31 de março de 2020. 


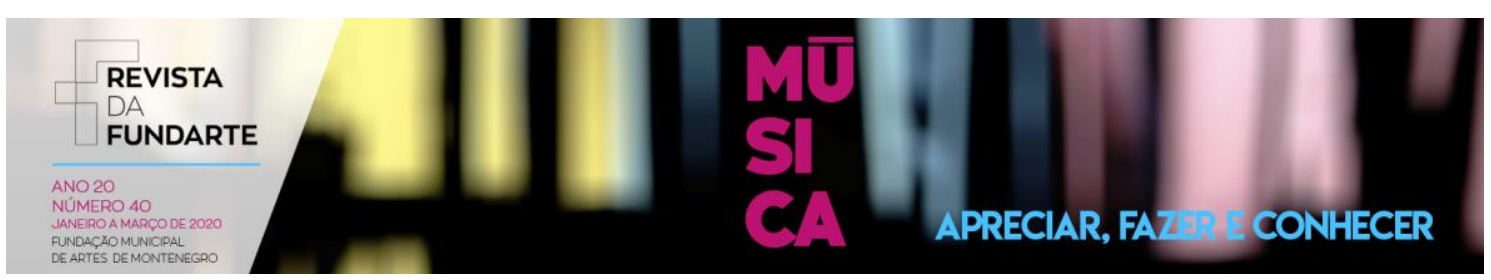

\title{
EDUCAÇÃO MUSICAL INCLUSIVA EM UM CURSO DE LICENCIATURA EM MÚSICA: RELATO DE UMA EXPERIÊNCIA
}

\author{
Maria Cecilia de A. R. Torres ${ }^{1}$ \\ Nisiane Franklin da Silva ${ }^{2}$
}

\begin{abstract}
Resumo: Este resumo contextualiza uma disciplina ofertada no sétimo semestre em um curso de Licenciatura em música na cidade de Porto Alegre/RS, através de cenas do que foi trabalhado por duas professoras que organizaram e ministraram as aulas no contexto da educação musical e da inclusão. A cada semestre emergiram interesses e discussões por parte dos discentes de conhecerem deficiências específicas. Partimos do conceito de inclusão, educação inclusiva e educação musical inclusiva, mesclando atividades teórico/reflexivas, práticas e palestras com convidados, propiciando diálogos também com o campo da educação especial. Finalizamos destacando a importância de continuarmos a trabalhar nessa perspectiva, pois temos muito a conhecer e a aprender.
\end{abstract}

Palavras-chave: educação musical inclusiva, licenciatura em música, formação docente

\section{INCLUSIVE MUSIC EDUCATION IN A MUSIC DEGREE COURSE: AN EXPERIENCE REPORT}

\begin{abstract}
This abstract contextualizes a subject offered during the 7th semester of a Music Teaching graduation course in Porto Alegre, RS, through scenes of the work done by two teachers who organized and taught classes in the context of music teaching and inclusion. Each semester, interests and discussions initiated by students have emerged, towards learning about specific disabilities. We began with the concept of inclusion, inclusive education and inclusive musical education, mixing theoretic and reflective activities with practices and lectures by guests, enabling dialogues with the field of special education. We finish by highlighting the importance of continuously working under this perspective, because there is so much to get to know and to learn.
\end{abstract}

Keywords: inclusive musical education, music teaching, teachers' formation.

\footnotetext{
${ }^{1}$ Mestre em Educação pela PUCRS e doutora em Educação pela UFRGS. Atuou por mais de 20 anos como professora de música em Escolas de Educação Básica. Desde 2008 é docente aposentada do Curso de Licenciatura em Música do Centro Universitário Metodista/IPA e foi Coordenadora da área da Música e Institucional do Projeto PIBID/CAPES/IPA. É pesquisadora desde 1996 do EMCO/PPG/Música UFRGS (CNPq), sob a coordenação da profa. Dra. Jusamara Souza e também é pesquisadora convidada do Grupo de Pesquisa NARRAMUS da UFSM (CNPq), trabalhando com pesquisa (auto)biográfica.

2 Mestre em Educação Musical pelo Programa de Pós Graduação da Universidade Federal do Rio Grande do Sul(UFRGS). Professorado Curso de Licenciatura em Músicado Centro Universitário Metodista IPA. Coordenadora pedagógica do Projeto OUVIRAVIDA, educação musical popular. Integraogrupo PITOCANDO, um espetáculo demúsica para crianças e o grupo musical CIRANDÔ. Integraoprojeto Concertos Didáticos da Orquestra da ULBRA ministrando cursos de formação de professor. Professora de piano,musicalização, prática de conjunto e de teoria e percepção musical.
}

TORRES, Maria Cecilia de A. R.; SILVA, Nisiane Franklin da. Educação musical inclusiva em um curso de licenciatura em música: relato de uma experiência. Revista da FUNDARTE. Montenegro, p.215-231, ano 20, № 40, janeiro/março de 2020.

Disponível em: http://.seer.fundarte.rs.gov.br/index.php/RevistadaFundarte/index> 31 de março de 2020. 


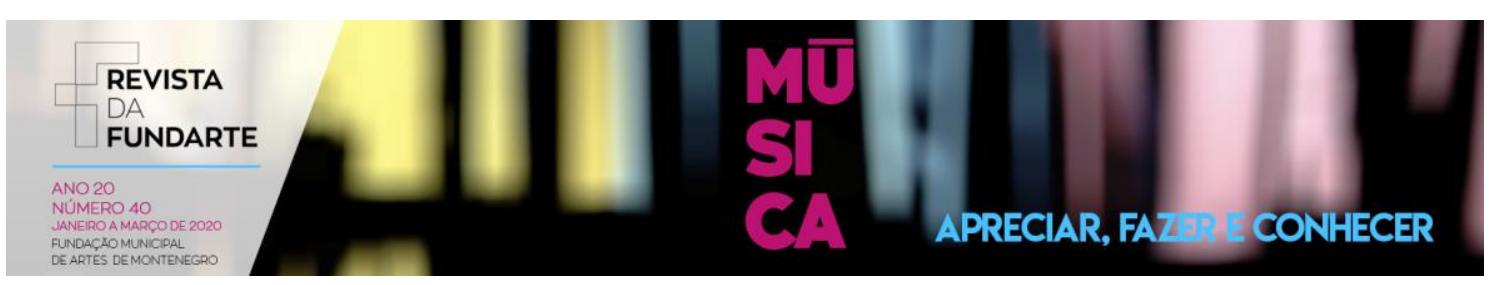

\section{Introdução}

No Brasil, apesar de as práticas educativas inclusivas estarem previstas em documentos oficiais que regulamentam o acesso de alunos com deficiências nas escolas de educação básica, sabe-se, pelo depoimento de profissionais (professores, diretores e coordenadores pedagógicos) que atuam nessas escolas, que a inclusão não foi completamente entendida, apropriada e estruturada pelas instituições de ensino e, em especial, para os cursos formadores de professores de música (ver Finck, 2009; Finck; Soares, 2010; Schambeck, 2014) .(SCHAMBECK, 2016, p.29).

Nos limites deste relato de experiência e inspiradas pela citação de Schambeck, apresentamos a contextualização de uma disciplina que é ofertada durante o sétimo semestre em um curso de Licenciatura em música no Centro Universitário Metodista/IPA, na cidade de Porto Alegre, Rio Grande do Sul, através de fragmentos e cenas do que foi trabalhado por duas docentes que organizaram e ministraram esta disciplina, com o propósito de oportunizar leituras, discussões e socializar atividades práticas no contexto da educação musical, da inclusão e da educação especial em um curso de formação de docentes de música.

Ressaltarmos aqui que a narrativa/escrita deste texto é uma trama das vozes de nós duas, docentes dessa disciplina, que vão sendo entrelaçadas por reflexões coletivas, questionamentos, descobertas e trocas de textos amalgamadas com os desafios constantes de selecionar temáticas e organizar uma escrita compartilhada, como neste relato de experiência.

Ao longo do curso os alunos têm uma disciplina obrigatória de Libras, no quarto semestre, na qual os discentes podem conhecer e ter noções básicas desta língua na perspectiva de educadores musicais que vão trabalhar no contexto da inclusão e, desta forma, foi possível observar alguns alunos que aprofundaram seus conhecimentos neste sentido, fazendo seus estágios supervisionados e Relatórios de Conclusão de Curso (RCC) com esta abordagem, associando o cantar e a língua de sinais, por exemplo.

TORRES, Maria Cecilia de A. R.; SILVA, Nisiane Franklin da. Educação musical inclusiva em um curso de licenciatura em música: relato de uma experiência. Revista da FUNDARTE. Montenegro, p.215-231, ano 20, oㅜ 40, janeiro/março de 2020.

Disponível em: http://.seer.fundarte.rs.gov.br/index.php/RevistadaFundarte/index> 31 de março de 2020. 


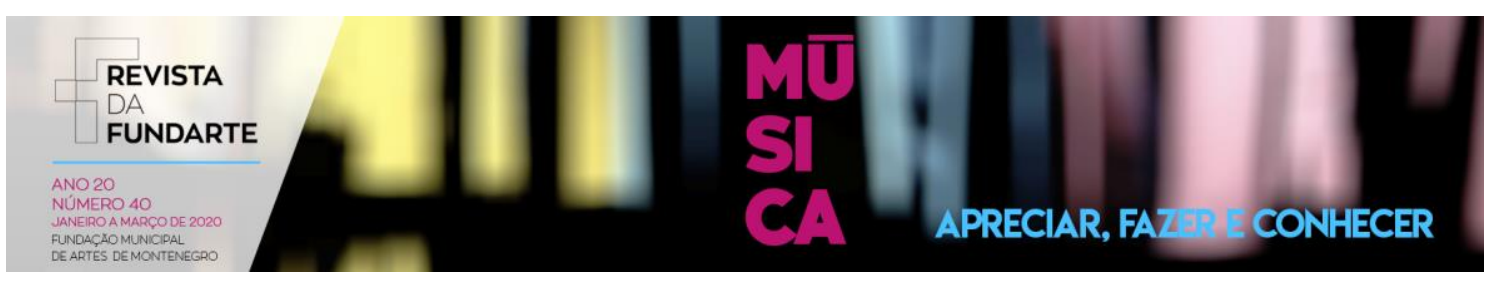

A disciplina de educação musical inclusiva acontece no sétimo semestre do curso e tem encontros semanais, perfazendo um total de 18 aulas, englobando leituras de textos que abordam diferentes deficiências e o fazer musical, discussões, escritos sobre temáticas distintas e reflexões teóricas, visitas a espaços de inclusão e a acolhida de palestrantes que socializem suas experiências pedagógicas e musicais em diferentes contextos de inclusão. Oportunizamos também atividades com a análise de filmes, documentários e a criação de materiais musicais para um trabalho com alunos de inclusão. Tentamos, no decorrer de cada semestre, oferecer um panorama geral do tema inclusão no contexto da educação e da educação musical, fazendo escolhas quanto às temáticas específicas que cada grupo gostaria de estudar e buscando o aprofundamento um pouco maior de determinadas temáticas, tais como inclusão na perspectiva de deficiências físicas, mentais e cognitivas, sociais e culturais.

Cabe destacar ainda que nós duas tivemos a experiência com 0 PIBID/CAPES (Programa Institucional de Bolsas de Iniciação à docência), com um subprojeto de Música que atuou durante três anos em uma Escola Estadual de Educação Especial na cidade de Porto Alegre com turmas de crianças, adolescentes e adultos jovens, sob a supervisão da professora de Artes da Escola e das supervisoras do Subprojeto PIBID/Música, realizando atividades musicais com os alunos. Estivemos nesta Escola entre o período de março de 2014 a dezembro de 2016, e este trabalho rendeu muitas aprendizagens e desafios para nós e para os bolsistas do PIBID. Um desafio constante para os licenciandos bolsistas e suas supervisoras neste trabalho com alunos com síndrome de Down, Transtorno do Espectro Autista (TEA), Paralisia Cerebral (PC), esquizofrenia, dentre outras, na perspectiva de compartilharem a docência e de fazerem música coletivamente. No ano de 2017, entre março e dezembro, o PIBID/Música deu continuidade ao trabalho em uma Escola Estadual de Ensino Fundamental que tinha muitos alunos de inclusão. Ao longo desses quatro anos do Subprojeto PIBID/Música nessas duas escolas, os bolsistas e suas supervisoras realizaram muitas práticas musicais coletivas envolvendo o cantar, tocar instrumentos, criar e improvisar, trabalhar ritmos

TORRES, Maria Cecilia de A. R.; SILVA, Nisiane Franklin da. Educação musical inclusiva em um curso de licenciatura em música: relato de uma experiência. Revista da FUNDARTE. Montenegro, p.215-231, ano 20, oㅜ 40, janeiro/março de 2020.

Disponível em: http://.seer.fundarte.rs.gov.br/index.php/RevistadaFundarte/index> 31 de março de 2020. 


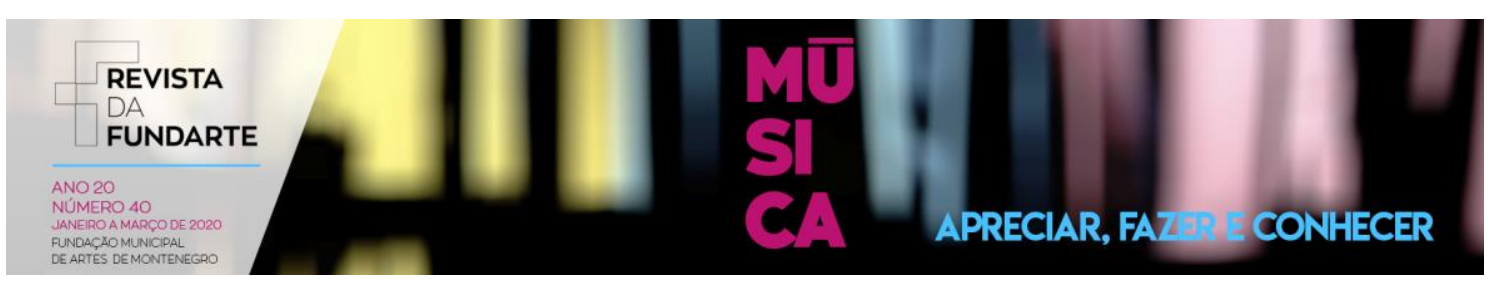

corporais, e também organizaram resumos acadêmicos, apresentações em eventos científicos e apresentações musicais coletivas.

Sabemos da amplitude do termo inclusão/inclusiva e não temos a pretensão de esgotar nenhum tópico, mas sim de conhecermos alguns autores que pesquisam e discutem sobre essas temáticas em diferentes contextos e perspectivas, oportunizando dessa forma que os discentes possam escolher seus temas de interesse e, dessa maneira, possam se aprofundar com a organização e apresentação de um Seminário, seleção e sugestão de outros textos, vídeos, filmes, links e a pesquisa de Instituições educacionais em que acontece o trabalho de educação musical inclusiva.

Nessa perspectiva aprendemos uns com os outros e a cada semestre o cronograma e a programação das aulas sofre alguma alteração, com mudanças e ampliação nos textos, inserção de atividades e práticas que buscam atender aos interesses dos discentes e futuros educadores musicais de cada grupo.

\section{Vamos assistir a um filme?}

O projeto de extensão Cine Inclusão se propõe a exibir filmes que apresentem temáticas inclusivas, seguidos de debates ministrados por pessoas previamente escolhidas com domínio do assunto [...] Para o desenvolvimento deste, a equipe seleciona obras cinematográficas e as assiste a fim de determinar as temáticas, o público alvo e os debatedores, de acordo com o título que será exibido. A sessão ocorre com a projeção dos filmes e, em seguida, os convidados norteiam a discussão, com intuito de instigar o pensamento crítico dos participantes, promovendo a reflexão sobre a inclusão (DUBAL e OLIVEIRA, 2017, p.1).

Em sintonia com a citação de Dubal e Oliveira (2017), após a entrega, leitura e discussão do Plano de Ensino com os alunos, conversamos sobre os calendários de trabalhos e avaliações do semestre e iniciamos nossos trabalhos, tendo como uma das primeiras atividades a apresentação de uma relação de filmes e documentários que abordam diferentes tipos de deficiências e cada aluno escolhe

TORRES, Maria Cecilia de A. R.; SILVA, Nisiane Franklin da. Educação musical inclusiva em um curso de licenciatura em música: relato de uma experiência. Revista da FUNDARTE. Montenegro, p.215-231, ano 20, oㅜ 40, janeiro/março de 2020.

Disponível em: http://.seer.fundarte.rs.gov.br/index.php/RevistadaFundarte/index> 31 de março de 2020. 


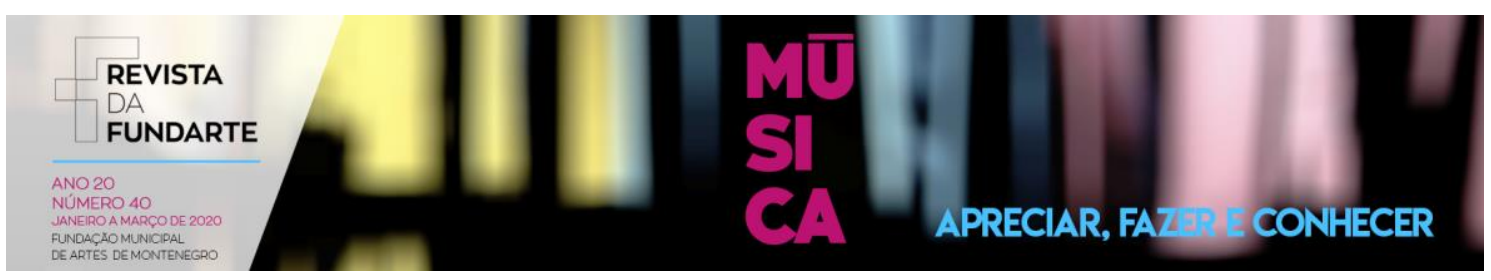

um, para assistir e organizar uma sinopse, para apresentar e discutir em aula. Trazemos assim nos limites deste texto alguns dos títulos da lista que a cada semestre se amplia com novos filmes e, a cada nova turma, alguns são retirados e outros substituídos.

Organizamos e entregamos a sinopse de alguns destes filmes e nos outros sugeridos, colocamos o título e o tipo de deficiência abordada, para que possam escolher o que mais agrada. A seguir apresentamos uma breve lista de títulos que foram assistidos e escolhidos por algum discente e socializados em sala de aula:

1. Meu filho meu mundo (TEA/Transtorno do espectro autista)

2. Rain man (TEA/Transtorno do espectro autista)

3. Vermelho como o céu (deficiência visual)

4. Os filhos do silêncio (deficiência auditiva)

5. A família Bélier (deficiência auditiva)

6. Colegas (Síndrome de Down)

7. O guardião de Memórias (Síndrome de Down)

8. Liberdade para as borboletas (deficiência visual)

9. Simples como amar (deficiência mental)

10. Gilbert Grape - Aprendiz de sonhador (deficiência mental)

11. O Filho eterno (Síndrome de Down)

12. Cordas (Curta que aborda a paralisia cerebral)

13. Uma lição de amor (Deficiência mental)

14. Meu nome é Radio ( Inclusão)

15. O escafandro e a borboleta (AVC/paralisia)

16. Somos todos diferentes/ Como estrelas na Terra (Trata de um menino com dislexia)

17. O líder da classe (Síndrome de Tourette)

18. Janela da alma (Cegueira)

TORRES, Maria Cecilia de A. R.; SILVA, Nisiane Franklin da. Educação musical inclusiva em um curso de licenciatura em música: relato de uma experiência. Revista da FUNDARTE. Montenegro, p.215-231, ano 20, no 40, janeiro/março de 2020.

Disponível em: http://.seer.fundarte.rs.gov.br/index.php/RevistadaFundarte/index $>31$ de março de 2020. 


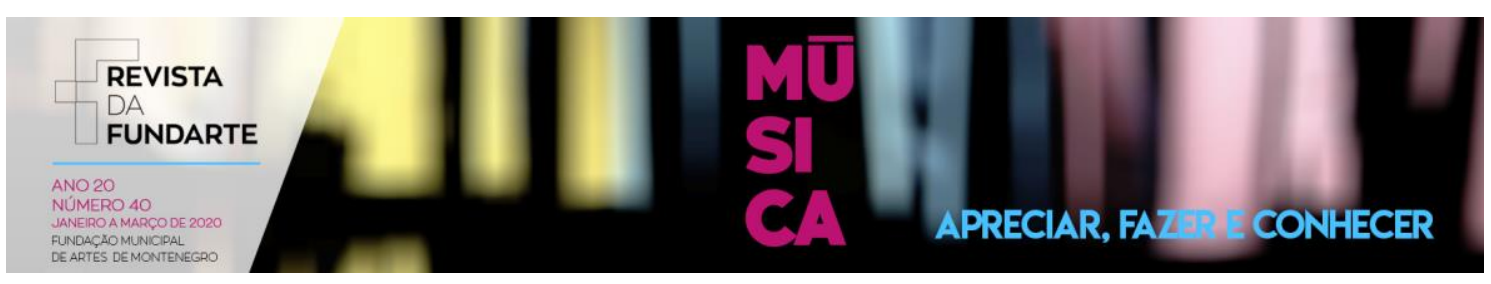

Esta atividade gera, ao longo de cada semestre, a apresentação de sinopses distintas, discussões a respeito dos temas e das abordagens com a narrativa fílmica e certamente, desencadeia o desejo de conhecermos mais sobre cada uma das deficiências ou processos de inclusão. Nesta perspectiva trago as reflexões de Louro (2012) a respeito do paradigma do suporte, onde a autora reflete sobre a educação musical e as aulas de música na perspectiva da inclusão, e ressalta que para que isso aconteça "é necessário que haja um suporte (social, econômico, físico ou instrumental), um meio que garanta o acesso a todo e qualquer recurso da comunidade" (LOURO, 2012, p.27).

A cada semestre pensamos em organizar um cronograma com as atividades, no sentido de termos um roteiro de cada encontro, mas que sempre está sujeito a inserções e mudanças tais como, a de trazer um grupo coral de inclusão de uma escola pública da região, a partir da sugestão de uma aluna e fazermos um evento para todos os alunos com direito à música, depoimentos e perguntas. Em outros momentos, foi possível termos convidadas que falaram sobre seus trabalhos com música e artes em espaços de inclusão, como no caso de uma das professoras que trouxe um documentário sobre o seu mestrado em Reabilitação, que abordava as danças circulares com pacientes adultos na sua grande maioria, com esquizofrenia. Tivemos também uma psicanalista e atriz convidada que falou de seu trabalho de teatro e música com crianças e jovens da FADEM - Fundação de Atendimento de Deficiência Múltipla, projetando vídeos das atividades práticas e comentando com os alunos.

Nos últimos dois semestres, incluímos ainda uma visita à Sala de recursos da Instituição onde estudam, com direito à explanação por parte da responsável pela Sala, sobre as políticas de inclusão institucionais, os materiais que existem para uso dos alunos de inclusão tais como, uma impressora em Braille, a presença de intérpretes de Libras e outras questões fundamentais para a inclusão dos discentes que estão cursando diferentes áreas nesta Instituição de Ensino Superior.

\section{Quais leituras fazer? Organizando o referencial teórico a cada semestre}

TORRES, Maria Cecilia de A. R.; SILVA, Nisiane Franklin da. Educação musical inclusiva em um curso de licenciatura em música: relato de uma experiência. Revista da FUNDARTE. Montenegro, p.215-231, ano 20, no 40, janeiro/março de 2020.

Disponível em: http://.seer.fundarte.rs.gov.br/index.php/RevistadaFundarte/index> 31 de março de 2020. 


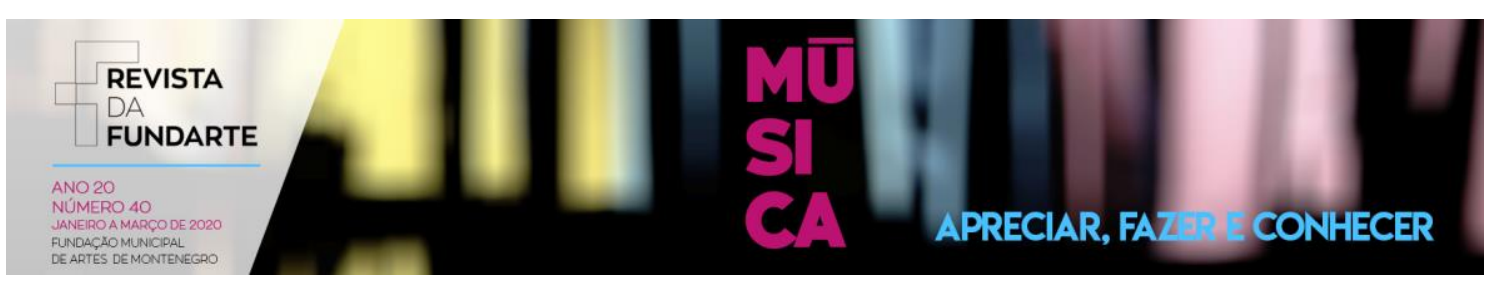

Um dos textos iniciais para leitura na disciplina costuma ser o livro "Construindo as Trilhas para Inclusão" organizado por GOMES (2009). O livro apresenta proposições teórico-práticas de renomados autores nacionais e internacionais na área da inclusão. Aborda os principais desafios existentes na escola em relação a dificuldades de aprendizagem, diferentes síndromes, transtornos e deficiências. Também reflete sobre os espaços públicos de educação. PACHECO (2009), questiona o modelo de nossas instituições escolares que ofertam um padrão único de educação para um público diverso.

Jovens portadores de desigualdades acorrem às escolas, por via de um processo de massificação. Tratando os 'desiguais como se fossem iguais, 'em pé de igualdade', como geralmente acontece, não apenas mantemos a desigualdade, como a aumentamos. (PACHECO, 2009, p.24).

Para PACHECO (2009), práticas de ensino em que predominam o método expositivo, que mantém a disposição dos alunos na sala de aula em filas voltadas para o professor, que não propõe estratégias específicas para potencializar o aprendizado dos alunos que aprendem em um ritmo mais lento, precisam ser repensadas. Afirma que é necessário ter uma "gestão diversificada do currículo", especialistas integrados às equipes de projetos escolares e uma "efetiva diversificação das aprendizagens" (p. 27).

A 'diferença' é normal, não é deficiente. A sociedade é formada por identidades plurais, particularidades, especificidades. Anormal é pautar o trabalho escolar pela igualdade. Deficientes são as práticas escolares que assentam no pressuposto de que somos todos iguais, que homogeneizam 0 que é diverso, mascarando ou negando as diferenças. (PACHECO, 200, p. 26).

As escolas precisam reorganizar-se para que a inclusão de fato se concretize e garanta oportunidades educacionais para todos.

Outro livro utilizado para leitura na disciplina é "Caminhos para Inclusão" de José Pacheco (2006). O livro faz parte do projeto Leonardo da Vinci denominado "Melhoramento da habilidade dos professores quanto à inclusão", (em inglês ETAI),

TORRES, Maria Cecilia de A. R.; SILVA, Nisiane Franklin da. Educação musical inclusiva em um curso de licenciatura em música: relato de uma experiência. Revista da FUNDARTE. Montenegro, p.215-231, ano 20, oㅜ 40, janeiro/março de 2020.

Disponível em: http://.seer.fundarte.rs.gov.br/index.php/RevistadaFundarte/index> 31 de março de 2020. 


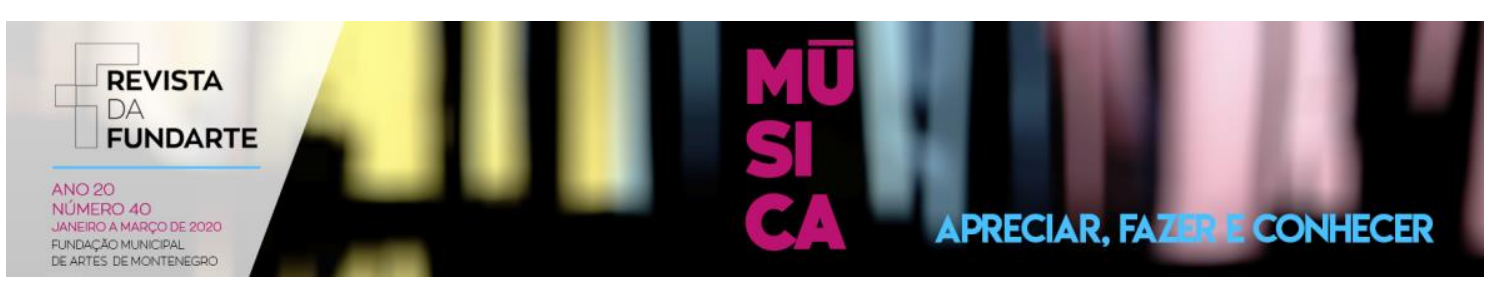

feito por uma equipe colaborativa da Áustria, Islândia, Portugal e Espanha. É organizado em três partes, a primeira e a segunda apresentam o projeto, a metodologia utilizada na pesquisa e a discussão dos resultados. A terceira parte apresenta um "Guia para aprimoramento da equipe docente", e aborda os seguintes temas: preparação para a educação escolar, planejamento curricular, prática em sala de aula, colaboração e coordenação, interação social dos alunos, colaboração lar-escola, avaliação e apreciação, serviços de apoio e desenvolvimento do quadro de pessoal. Todos esses temas são abordados pelo autor na perspectiva de que

as práticas pedagógicas em uma escola inclusiva precisam refletir uma abordagem mais diversificada, flexível e colaborativa do que uma escola tradicional. A inclusão pressupõe que a escola se ajuste a todas crianças que desejam matricular-se em sua localidade, em vez de esperar que uma determinada criança com necessidades especiais se ajuste à escola (integração) (PACHECO, 2006, p. 13).

Um dos aspectos centrais da disciplina tem sido a seleção de artigos e trabalhos que abordem as deficiências diversas na perspectiva da educação musical/música, como também buscar atender às demandas de cada grupo, com a inclusão de novas leituras e temas para reflexão.

Costumamos organizar e entregar uma lista de textos, na sua grande maioria com os links na internet para baixar e ler e, desta forma, ir ampliando com a pesquisa de vídeos, reportagens no youtube e depoimentos que complementem estas aprendizagens. Listamos a seguir alguns dos artigos e trabalhos que foram compondo o nosso material de leituras, com sugestões trazidas pelas docentes e também pelos alunos e por colegas, em um processo de ampliação dos saberes, oportunizando o debate em torno de dúvidas e interesses distintos.

\begin{tabular}{|c|c|c|}
\hline $\begin{array}{c}\text { Título do artigo ou } \\
\text { pesquisa }\end{array}$ & Autor/es & $\begin{array}{c}\text { Fonte e ano de } \\
\text { publicação }\end{array}$ \\
\hline
\end{tabular}

TORRES, Maria Cecilia de A. R.; SILVA, Nisiane Franklin da. Educação musical inclusiva em um curso de licenciatura em música: relato de uma experiência. Revista da FUNDARTE. Montenegro, p.215-231, ano 20, oㅜ 40, janeiro/março de 2020.

Disponível em: http://.seer.fundarte.rs.gov.br/index.php/RevistadaFundarte/index> 31 de março de 2020. 


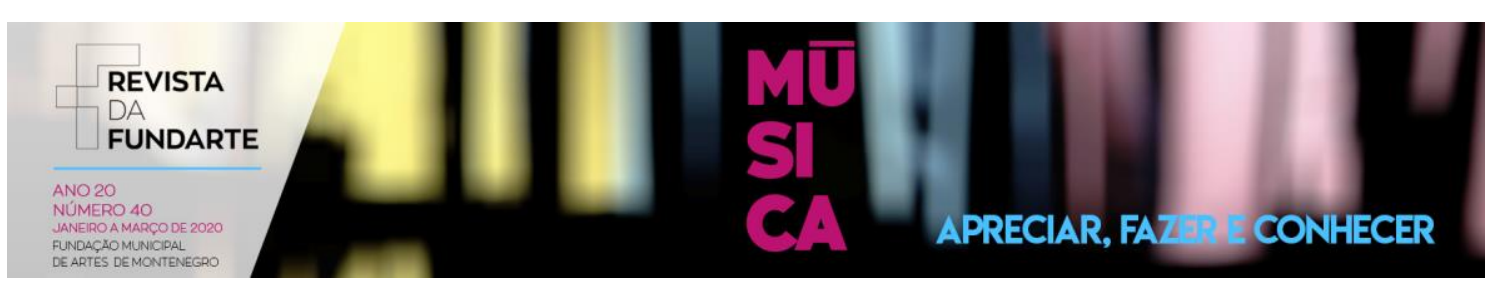

\begin{tabular}{|c|c|c|}
\hline $\begin{array}{l}\text { 1.Musicalização para } \\
\text { Surdos: contextualização e } \\
\text { possibilidades de } \\
\text { abordagem. }\end{array}$ & $\begin{array}{l}\text { Ivo Vieira Gomes } \\
\text { Laysa Maria Akeho }\end{array}$ & $\begin{array}{l}\text { Revista } \\
\text { Formação@Docente } \\
\text { - Bel Horizonte - vol. 6, } \\
\text { n. 2, jul/dez 2014. }\end{array}$ \\
\hline $\begin{array}{l}\text { 2. Desenvolvimento de } \\
\text { Habilidades Musicais em } \\
\text { Crianças Autistas: Um } \\
\text { Projeto de Extensão e } \\
\text { Pesquisa. }\end{array}$ & $\begin{array}{lll}\text { Claudia } & \text { Eboli } & \text { C. } \\
\text { Santos } & & \\
\end{array}$ & 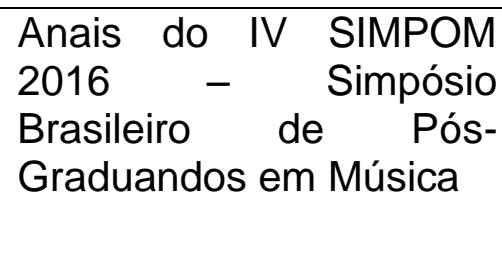 \\
\hline $\begin{array}{l}\text { 3. Ações pedagógicas para } \\
\text { inclusão de aluno com } \\
\text { transtorno do espectro } \\
\text { autista numa escola de } \\
\text { música de São Paulo: } \\
\text { Relato de caso. }\end{array}$ & $\begin{array}{l}\text { Viviane dos Santos } \\
\text { Louro }\end{array}$ & $\begin{array}{l}\text { Revista Educação, Artes } \\
\& \text { Inclusão, UDESC, vol. } \\
10, \text { n. 2, } 2014\end{array}$ \\
\hline $\begin{array}{l}\text { 4. A inserção de estudantes } \\
\text { com deficiência visual em } \\
\text { cursos de Licenciatura em } \\
\text { Música: um estudo de caso } \\
\text { na Universidade Estadual } \\
\text { do Rio Grande do Sul. }\end{array}$ & $\begin{array}{l}\text { Daltro Keenan Júnior } \\
\text { Morgana Kremer }\end{array}$ & $\begin{array}{l}\text { Revista da Fundarte, ano } \\
18, \text { n.35, } 2018 .\end{array}$ \\
\hline $\begin{array}{l}\text { 5. Educação Musical Para } \\
\text { Crianças da Etnia Maguta } \\
\text { no Alto Solimões. }\end{array}$ & Jeane Colares da Silva & $\begin{array}{l}\text { Nexus- } \quad \text { Revista de } \\
\text { Extensão do IFAM, vol.1, } \\
\text { n.1,2015 }\end{array}$ \\
\hline $\begin{array}{l}\text { 6. A aplicação do método } \\
\text { TUBS para alunos com } \\
\text { deficiência intelectual e } \\
\text { Síndrome de Down: um } \\
\text { relato de experiência. }\end{array}$ & $\begin{array}{lll}\begin{array}{l}\text { Luciano } \\
\text { Candemil }\end{array} & \text { da } & \text { Silva } \\
\end{array}$ & $\begin{array}{l}\text { Anais do XVII Encontro } \\
\text { Regional Sul da ABEM, } \\
\text { Curitiba, 2016. }\end{array}$ \\
\hline $\begin{array}{l}\text { 7. Música para crianças } \\
\text { com paralisia cerebral. }\end{array}$ & $\begin{array}{l}\text { Angelita Maria Vander } \\
\text { Broock }\end{array}$ & $\begin{array}{l}\text { Anais do XIV Encontro } \\
\text { Nacional da ABEM, Belo } \\
\text { Horizonte/MG, 2005. }\end{array}$ \\
\hline $\begin{array}{l}8 . \\
\text { metodológigicas utilizadas nas } \\
\text { metacação Musical de cegos } \\
\text { Educacos } \\
\text { a partir da abordagem Orff- } \\
\text { Schulwerk. }\end{array}$ & $\begin{array}{l}\text { Isabel Cristina Dias } \\
\text { Bertevelli }\end{array}$ & $\begin{array}{ll}\text { Revista } & \text { Eletrônica } \\
\text { Pesquiseduca } & \text { v.2, n. 4, } \\
2010 . & \end{array}$ \\
\hline
\end{tabular}

TORRES, Maria Cecilia de A. R.; SILVA, Nisiane Franklin da. Educação musical inclusiva em um curso de licenciatura em música: relato de uma experiência. Revista da FUNDARTE. Montenegro, p.215-231, ano 20, oㅜ 40, janeiro/março de 2020.

Disponível em: http://.seer.fundarte.rs.gov.br/index.php/RevistadaFundarte/index> 31 de março de 2020. 


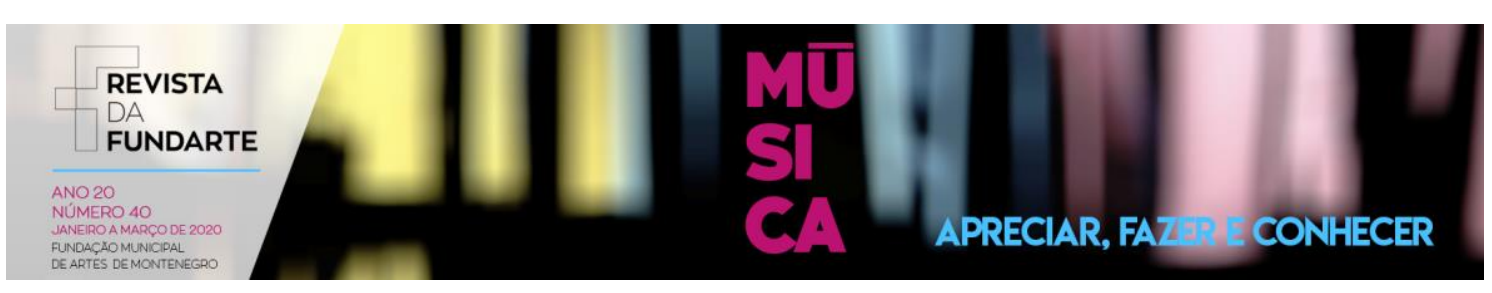

\begin{tabular}{|c|c|c|}
\hline $\begin{array}{l}\text { 9. Música na Educação } \\
\text { Especial: jogos adaptados. }\end{array}$ & $\begin{array}{l}\text { Elton Mendes Pinheiro } \\
\text { Jorge Octavio Batista } \\
\text { Filipe Busana Dias } \\
\text { Maria Luiza Amaral }\end{array}$ & $\begin{array}{l}\text { Anais do XVII Encontro } \\
\text { Regional Sul da ABEM, } \\
\text { Curitiba, 2016. }\end{array}$ \\
\hline $\begin{array}{l}10 . \text { Atividades musicais } \\
\text { para alunos público alvo da } \\
\text { educaçãor especial: } \\
\text { aplicação e avaliação. }\end{array}$ & $\begin{array}{l}\text { Ana Célia de Lima } \\
\text { Viana } \\
\text { Tânia Maria de Rose }\end{array}$ & $\begin{array}{l}\text { Anais do VIII Encontro da } \\
\text { Associação Brasileira de } \\
\text { Pesquisadores em Educ. } \\
\text { Especial, Londrina, } 2013 .\end{array}$ \\
\hline $\begin{array}{l}\text { 11. Educação Musical e } \\
\text { inclusão: possibilidades de } \\
\text { atuação. }\end{array}$ & $\begin{array}{l}\text { Regiana Blank Wille } \\
\text { Luana Medina } \\
\text { Andréia de Souza } \\
\text { Lang } \\
\text { Diocelena Miranda }\end{array}$ & $\begin{array}{ll}\text { Revista } & \text { Expressão, } \\
\text { Pelotas, v.23, n.3, } 2018 .\end{array}$ \\
\hline $\begin{array}{l}\text { 12. Inclusão de alunos com } \\
\text { deficiência na sala de aula: } \\
\text { tendências de pesquisa e } \\
\text { impactos na formação do } \\
\text { professor de música. }\end{array}$ & $\begin{array}{ll}\text { Regina } & \text { Finck } \\
\text { Schambeck }\end{array}$ & $\begin{array}{lll}\text { Revista da } & \text { ABEM. } \\
\text { Londrina, v.24, } & \text { n.36, } \\
\text { jan.jun. 2016 } & \end{array}$ \\
\hline $\begin{array}{l}\text { 13. A educação musical } \\
\text { inclusiva na escola de } \\
\text { educação básica: o que o } \\
\text { professor de música precisa } \\
\text { saber? }\end{array}$ & $\begin{array}{l}\text { Crislany Viana da Silva } \\
\text { Cristiane Maria } \\
\text { Galdino de Almeida }\end{array}$ & $\begin{array}{lr}\text { Anais do II } & \text { Congresso } \\
\text { Internacional } & \text { de } \\
\text { Educação Inclusiva. II } \\
\text { Jornada } \\
\text { Brasileira de } \\
\text { Inclusilena } \\
\text { Inclucação } \\
\text { 2016. }\end{array}$ \\
\hline $\begin{array}{l}\text { 14. Da tinta para o Braille: } \\
\text { a produção de partituras } \\
\text { para pessoas com } \\
\text { deficiência visual }\end{array}$ & $\begin{array}{l}\text { Fabiana } \\
\text { Bonilha }\end{array}$ & $\begin{array}{l}\text { Anais do XVIII Congresso } \\
\text { da Associação Nacional } \\
\text { de Pesquisa e Pós- } \\
\text { Graduação (ANPPOM) } \\
\text { Salvador-2008 }\end{array}$ \\
\hline
\end{tabular}

Estes foram alguns dos textos sugeridos para leitura e discussão e, ao longo do semestre outros materiais surgiram e foram compondo as referências de cada turma, a partir dos interesses e das experiências vividas pelos discentes de cada semestre.

Após o término dessas leituras, organizávamos Seminários em duplas ou individualmente, em que cada acadêmico escolhia o tema no qual gostaria de se aprofundar e preparava uma apresentação seguida de debate, com duração de 30 minutos, sobre a temática escolhida. Esta atividade gerou muitos debates, ampliou conhecimentos e oportunizou a inclusão de temática tais como, inclusão religiosa, TORRES, Maria Cecilia de A. R.; SILVA, Nisiane Franklin da. Educação musical inclusiva em um curso de licenciatura em música: relato de uma experiência. Revista da FUNDARTE. Montenegro, p.215-231, ano 20, oㅜ 40, janeiro/março de 2020.

Disponível em: http://.seer.fundarte.rs.gov.br/index.php/RevistadaFundarte/index> 31 de março de 2020. 


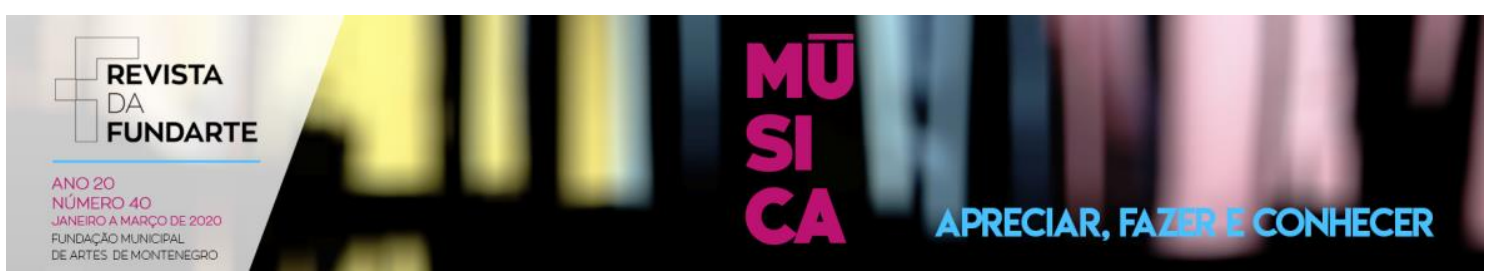

étnica com grupos indígenas e de refugiados, inclusão social com diversos grupos, além de síndromes de Tourette e música, Transtorno do espectro Autista (TEA), Paralisia cerebral, Surdez, cegueira, dentre outras.

Neste sentido, trazemos as reflexões de Wille, Medina, Lang e Miranda (2018), nas quais as autoras enfatizam em artigo sobre educação musical e inclusão que "A inclusão social ocorre a partir de um movimento, um processo em que a sociedade está de um lado, e as pessoas excluídas de outro, mas com o objetivo de juntarem esforços buscando igualdade, acesso e condições para todos" e complementam suas discussões apresentando várias ações documentadas, entre elas, a "Declaração de Sundberg (Unesco, 1981), a Declaração de Salamanca e Linha de Ação (Unesco, 1994), a Declaração Mundial de Educação para Todos nas Américas (Unicef, 2000)" (p.211).

\section{Braille e MusiBraille: aprendizagens e desafios para os licenciandos}

Em novembro de 2009, a Prefeitura de Porto Alegre recebeu o projeto Musibraille, desenvolvido pela professora Dolores Tomé da Universidade de Brasília (Unb) e pelo professor José Antônio Borges da Universidade Federal do Rio de Janeiro (UFRJ). Esse evento tinha como objetivo capacitar professores a trabalharem com músicos e estudantes cegos, o qual foi organizado na Usina do Gasômetro com entrada franca. Houve um grande interesse na turma de Educação Musical Inclusiva, em participar dessa formação e assim, organizamos as inscrições e realizamos o curso. É importante salientar que, na época, existiam poucos programas de computador disponíveis para a transcrição musical em braille e, os que existiam, eram caros e não faziam a emulação da voz para o português. Dessa forma, foi muito motivador conhecer um novo programa desenvolvido no Brasil, em português e gratuito.

Os idealizadores dessa proposta explicam que

O projeto Musibraille destina-se a criar condições favoráveis à aprendizagem musical das pessoas com deficiência visual que sejam equivalentes às dos colegas de visão normal. A técnica de Musicografia Braille é uma das principais ferramentas que permitem essa equivalência.

TORRES, Maria Cecilia de A. R.; SILVA, Nisiane Franklin da. Educação musical inclusiva em um curso de licenciatura em música: relato de uma experiência. Revista da FUNDARTE. Montenegro, p.215-231, ano 20, oㅜ 40, janeiro/março de 2020.

Disponível em: http://.seer.fundarte.rs.gov.br/index.php/RevistadaFundarte/index> 31 de março de 2020. 


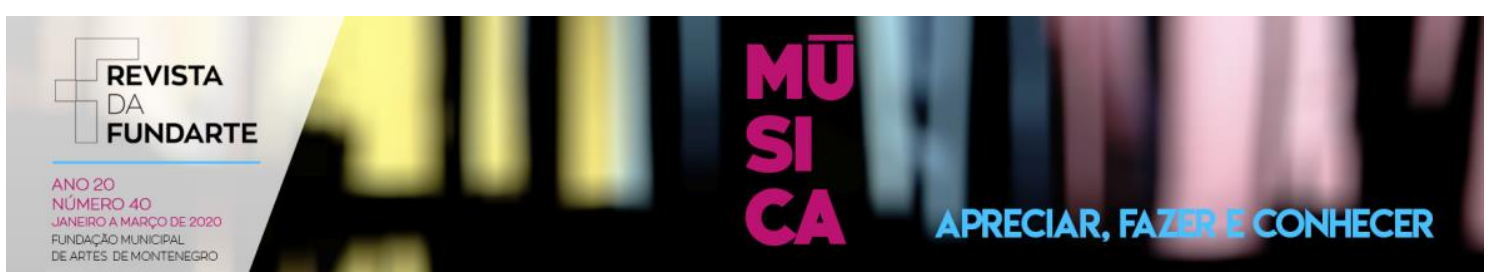

Ela foi desenvolvida em 1828 por Louis Braille, que adaptou a técnica para transcrição de textos anteriormente desenvolvida para a transcrição musical. Através desta técnica um texto musical de qualquer complexidade pode ser transcrito para a forma tátil e facilmente assimilado pelos deficientes visuais. (http://intervox.nce.ufrj.br/musibraille/oquee.htm acessado em 11/02/20).

Ao avaliarmos nossa aprendizagem no curso de Musibraille, observamos a necessidade de conhecer previamente o alfabeto braile, para termos um melhor aproveitamento e desempenho na escrita da musicografia braille. Assim, reorganizamos esse módulo da disciplina em duas etapas. A primeira voltada para conhecer e se apropriar do alfabeto braille, sua escrita e lelitura e a segunda, ampliar esse conhecimento para o aprendizado da escrita musical em braille.

Entramos nesse universo através de exercícios básicos como transcrever para o braille a letra de canções do folclore brasileiro, poemas e pequenas histórias; ler e transcrever em tinta as informações em braille contidas em embalagens de produtos alimentícios, de beleza, higiene e farmacêuticos; observar em diferentes ambientes como elevadores, bancos, supermercados, consultórios entre outros, indicações em braile, para praticar a leitura. Essas propostas oportunizaram momentos de muita descoberta para os discentes fomentando por um lado, o prazer de ter acesso a esse conhecimento e por outro, a reflexão sobre a necessidade de se ter mais investimento em políticas públicas de acessibilidade para os não videntes.

$\mathrm{Na}$ etapa do aprendizado da escrita musical em braille, iniciamos pela identificação dos caracteres que representam os elementos musicais como claves, fórmulas de compasso, figuras musicais, notas musicais, alterações, armaduras de clave, barras de compasso e barra final. Os exercícios eram realizados em uma folha impressa com "celas vazias", onde os alunos marcavam com caneta os pontos formadores de cada caractere, pois não tínhamos a reglete e a punção, equipamentos necessários para escrever em relevo.

O software Musibraille era utilizado de forma coletiva, através dos recursos de um computador com áudio e um projetor. Às vezes alguns alunos levavam seus TORRES, Maria Cecilia de A. R.; SILVA, Nisiane Franklin da. Educação musical inclusiva em um curso de licenciatura em música: relato de uma experiência. Revista da FUNDARTE. Montenegro, p.215-231, ano 20, oㅜ 40, janeiro/março de 2020.

Disponível em: http://.seer.fundarte.rs.gov.br/index.php/RevistadaFundarte/index> 31 de março de 2020. 


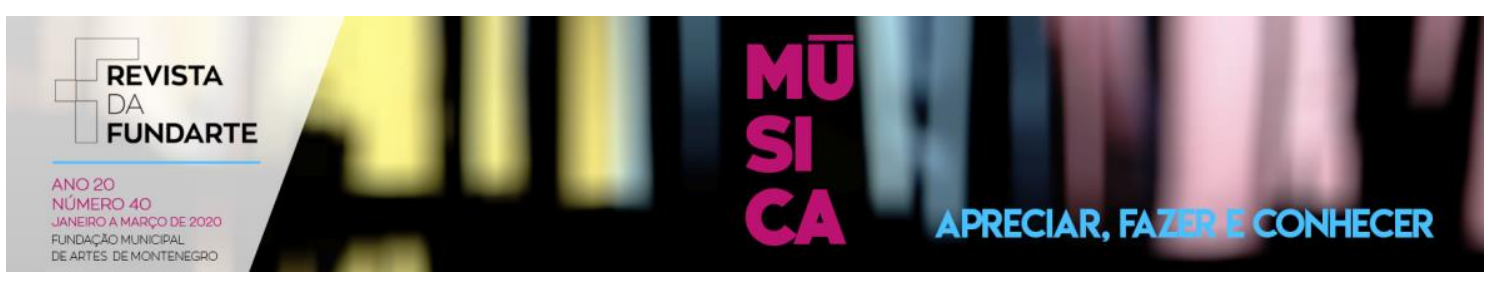

computadores pessoais possibilitando fazer um dinâmica de trabalho em grupos menores. O repertório escolhido variava entre canções folclóricas brasileiras, excertos de obras de concerto e composições dos próprios alunos.

\section{Entre livros, jogos, áudio partituras e materiais para a aula de música}

A última atividade de avaliação da disciplina tem sido a confecção de um material que os acadêmicos poderão usar na aula de música, no contexto da inclusão e a cada semestre, são várias ideias como a elaboração e audiodescrição de imagens em Libras, partituras em Braille, jogos de alfabetização musical e adaptação de digitação para o instrumento como a flauta doce para o Braille. Tivemos também histórias sonorizadas, jogos de memória auditiva, produção de livros em Braille.

Vale destacar alguns projetos tais como "Surdo para surdos", em que através do trabalho de percussão com os instrumentos surdo de primeira, que possui som mais grave e é tocado no primeiro tempo de cada compasso, surdo de segunda, que possui som médio-grave e é tocado no segundo tempo de cada compasso, e surdo de terceira, geralmente mais agudo e que faz respostas rítmicas livres, e o gestual de comunicação característico de Escolas de Samba, o trabalho oportunizava aos alunos ouvintes e não ouvintes a participarem das práticas musicais coletivas.

Em um outro projeto, o aluno desenvolveu um protótipo em que lâmpadas de diferentes cores acendiam e apagavam, através do acionamento de interruptores, possibilitando a percepção visual de ideias rítmicas executadas.

\section{Algumas reflexões}

Ao finalizarmos essas breves reflexões no contexto da educação musical e da educação inclusiva, temos consciência da amplitude e importância desse tema e do quanto ainda precisa ser trabalho, discutido e socializado, especificamente no campo da educação musical e da formação docente nos cursos de Graduação/Licenciaturas.

TORRES, Maria Cecilia de A. R.; SILVA, Nisiane Franklin da. Educação musical inclusiva em um curso de licenciatura em música: relato de uma experiência. Revista da FUNDARTE. Montenegro, p.215-231, ano 20, oㅜ 40, janeiro/março de 2020.

Disponível em: http://.seer.fundarte.rs.gov.br/index.php/RevistadaFundarte/index> 31 de março de 2020. 


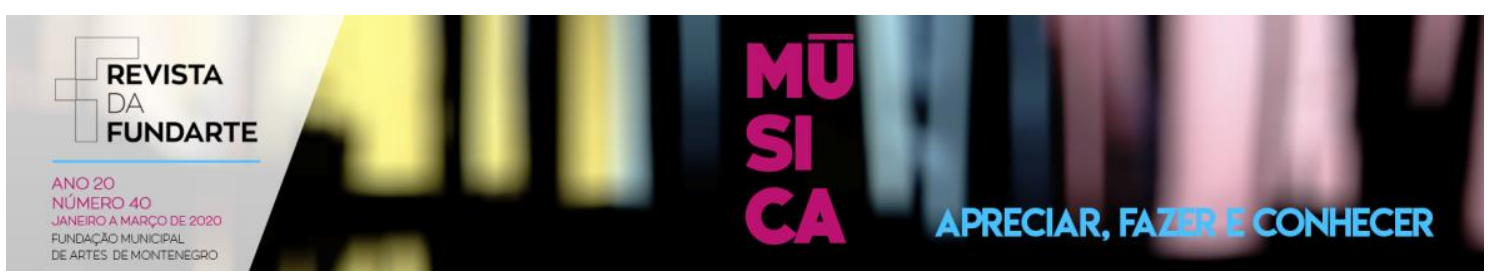

Trazemos as ideias de Silva e Almeida (2016) com as quais concordamos e nas quais as autoras enfatizam que:

\begin{abstract}
para o desenvolvimento de uma prática docente inclusiva não existe uma receita pronta e não é uma tarefa simples de ser desempenhada. Compreendemos o grande desafio que o professor de música precisa enfrentar para tornar significativa a educação musical para todos os alunos. Diante da defasagem do ensino público, da desvalorização do professor, da superlotação das salas de aula, do sucateamento das escolas, da falta de materiais necessários para se fazer música na escola, requerer do professor de música desempenhar esta tarefa tão complexa que é a inclusão, parece sobre-humano. (SILVA e ALMEIDA, 2016, p.9).
\end{abstract}

Salientamos ao longo da nossa escrita que a cada semestre e turma nova havia uma reconfiguração do cronograma, dos convidados e dos temas abordados em aula. Buscamos sempre dialogar com os discentes para conhecermos suas experiências e expectativas em relação a este campo de conhecimento, e, assim, possibilitarmos discussões, palestras e práticas significativas para os alunos.

Não tivemos a pretensão de esgotar essa temática nem de trazermos uma narrativa linear sobre a educação musical inclusiva, mas sim de socializarmos e dialogarmos com outros colegas e cursos que oferecem disciplinas semelhantes em cursos de Licenciatura em Música no sentido de ampliarmos nossos saberes e fazeres no espaço da educação musical inclusiva, como docentes formadores.

\title{
Referências:
}

BERTEVELLI, Isabel Cristina Dias. Estratégias metodológicas utilizadas na Educação Musical de cegos a partir da abordagem Orff-Schulwerk. Revista Eletrônica Pesquisaeduca v.2, n.4, 2010.

BONILHA, Fabiana Gouvêa. Da tinta para o Braille: a produção de partituras para pessoas com deficiência visual. Anais do XVII Congresso da ANPPOM, Salvador, 2008.

BROOCK, Angelita Maria Vander. Música para crianças com paralisia cerebral. Anais do XIV Encontro Nacional da ABEM, Belo Horizonte/MG, 2005.

CANDEMIL, Luciano da Silva. A aplicação do método TUBS para alunos com deficiência intelectual e Síndrome de Down: um relato de experiência. Anais do XVII Encontro Regional Sul da ABEM, Curitiba, 2016.

TORRES, Maria Cecilia de A. R.; SILVA, Nisiane Franklin da. Educação musical inclusiva em um curso de licenciatura em música: relato de uma experiência. Revista da FUNDARTE. Montenegro, p.215-231, ano 20, oㅜ 40, janeiro/março de 2020.

Disponível em: http://.seer.fundarte.rs.gov.br/index.php/RevistadaFundarte/index> 31 de março de 2020. 


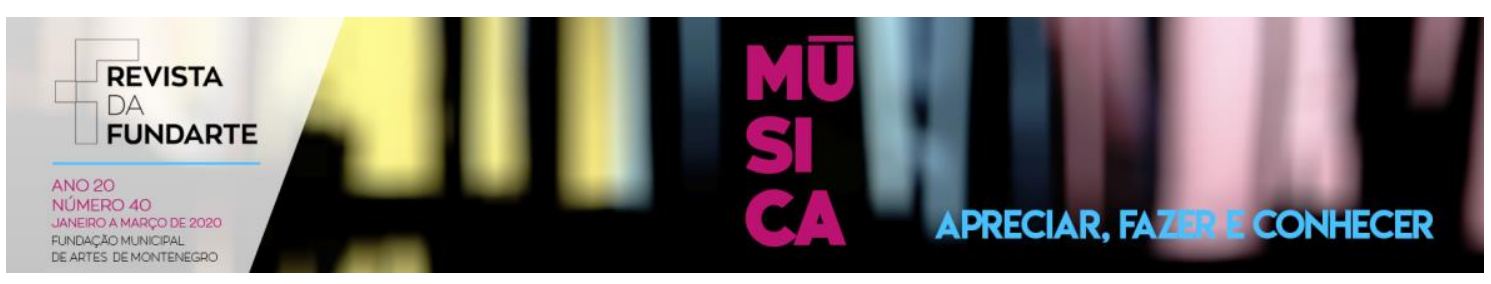

DUBAL, Aline Machado; OLIVEIRA, Dudlei Floriano. Cine inclusão: pensando a inclusão através do cinema. Revista Bem legal, UFRGS, V. 7, n.1, 2017.

GOMES, Ivo Vieira. AKEHO, Laysa Maria. Musicalização para Surdos: contextualização e possibilidades de abordagem.Revista Formação@Docente - Belo Horizonte - vol.6, n.2, jul/dez 2014.

GOMES, Márcio (Org.). Construindo as trilhas para a inclusão. Petrópolis, RJ: Vozes, 2009.

JÚNIOR, Daltro Keenan; KREMER, Morgana. A inserção de estudantes com deficiência visual em cursos de Licenciatura em Música: um estudo de caso na Universidade Estadual do Rio Grande do Sul. Revista da Fundarte, ano 18, n.35, 2018.

LOURO, Viviane. Fundamentos da Aprendizagem Musical da Pessoa com Deficiência.1 ${ }^{a}$ Edição. São Paulo: Editora Som, 2012.

PACHECO, José. Berços da desigualdade. In: Construindo as trilhas para a inclusão. Petrópolis, RJ: Vozes, 2009.

PINHEIRO, Elton Mendes; BATISTA, Jorge Octavio; DIAS, Filipe Busana; AMARAL, Maria Luiza. Música na Educação Especial: jogos adaptados. Anais do XVII Encontro Regional Sul da ABEM, Curitiba, 2016.

SANTOS, Claudia Eboli. Desenvolvimento de Habilidades Musicais em Crianças Autistas: Um Projeto de Extensão e Pesquisa. Anais do IV SIMPOM, 2016.

SCHAMBECK, Regina Fink. Inclusão de alunos com deficiência na sala de aula: tendências de pesquisa e impactos na formação do professor de música. Revista da ABEM, Londrina, v.24, n.36, jan/jun. 2016.

SILVA, Crislany Viana da, ALMEIDA, Cristiane Maria Galdino. Educação Musical Inclusiva na escola de Educação Básica: O que o professor de música precisa saber? Anais do II Congresso Internacional de Educação Inclusiva (II CINTEDI), Campina Grande/PB, 2016.

SILVA, Jeane Colares da. Educação Musical Para Crianças da Etnia Maguta no Alto Solimões. Nexus- Revista de Extensão do IFAM, vol.1, n.1, 2015.

VIANA, Ana Célia de Lima Viana; ROSE, Tânia Maria de. Atividades musicais para alunos público alvo da educação especial: aplicação e avaliação. Anais do VIII Encontro da Associação Brasileira de Pesquisadores em Educ. Especial, Londrina, 2013.

WILLE, Regiana Blank; MEDINA, Luana; LANG, Andréia de Souza; MIRANDA, Diocelena. Revista Expressa Extensão, v.23, n.3, Set/Dez, Pelotas, 2018.

TORRES, Maria Cecilia de A. R.; SILVA, Nisiane Franklin da. Educação musical inclusiva em um curso de licenciatura em música: relato de uma experiência. Revista da FUNDARTE. Montenegro, p.215-231, ano 20, no 40, janeiro/março de 2020 .

Disponível em: http://.seer.fundarte.rs.gov.br/index.php/RevistadaFundarte/index> 31 de março de 2020. 


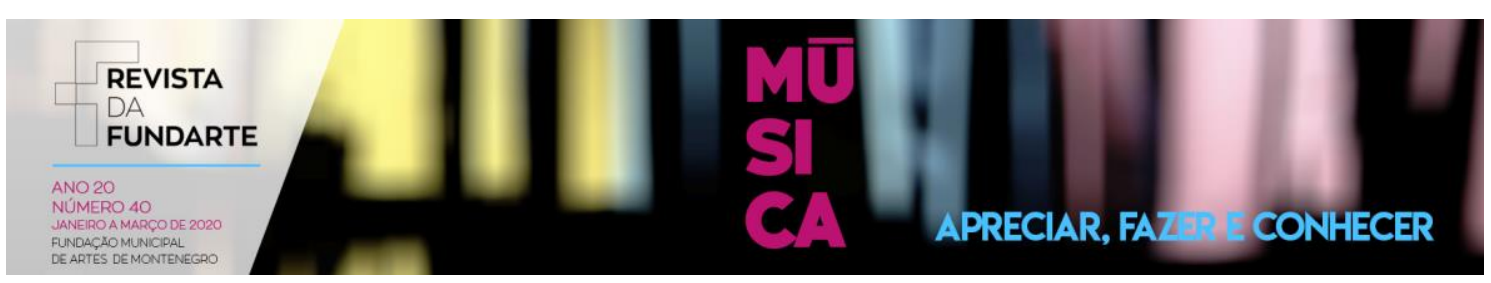

\section{Links dos filmes}

A família Bélier https://www.youtube.com/watch?v=KuGtmX8B6EE (trailer)

Colegas https://www.youtube.com/watch?v=olRt1b2puGc (trailer oficial)

Cordas https://www.youtube.com/watch?v=OrGEjSn1v8Y

Gilbert Grape Aprendiz de sonhador https://www.youtube.com/watch?v=wapJlcRCPcl

Janela da alma www.youtube.com/watch? $v=4 \mathrm{~F} 87 \mathrm{sHz} 6 \mathrm{y} 4 \mathrm{~s}$

Liberdade para as borboletas https://www.youtube.com/watch?v=zwIMb 3dSO0

Meu filho meu mundo https://www.youtube.com/watch?v=wEbl zBjANM

Meu nome é Radio https://www.youtube.com/watch?v=oDjYQ2ll1f4

O escafandro e a borboleta https://www.youtube.com/watch?v=8U1M0z0zkto

O filho eterno https://www.youtube.com/watch?v=JdPyZdSFIrA

O guardião de memórias https://www.youtube.com/watch?v=YK2NUELtLFE

Os filhos do silêncio https://www.youtube.com/watch?v=Jnjlp4XYSeY

O líder da classe https://www.youtube.com/watch?v=q6bLLKT1Wv4

Rain Man https://www.youtube.com/watch?v=mINwXuHUA8I (trailer)

Simples como amar https://www.youtube.com/watch?v=cwGKAISZ5CA

Somos todos diferentes/Como estrelas na Terra https://www.youtube.com/watch?v=6rxSS46Fwk4

Uma lição de amor https://vimeo.com/197340552

Vermelho como o céu https://www.youtube.com/watch?v=yvd9R30hNak

TORRES, Maria Cecilia de A. R.; SILVA, Nisiane Franklin da. Educação musical inclusiva em um curso de licenciatura em música: relato de uma experiência. Revista da FUNDARTE. Montenegro, p.215-231, ano 20, oㅜ 40, janeiro/março de 2020.

Disponível em: http://.seer.fundarte.rs.gov.br/index.php/RevistadaFundarte/index> 31 de março de 2020. 